\title{
Scientific and Practical Support For Studying The Personality and Environment Of Convicts
}

\author{
Guzalkhon Akhmedova \\ (DSc) Lecturer, Department of Criminalistic \& Forensic Science, Tashkent state university of law, E-mail: \\ guzal_nc@yahoo.com. ORCID 0000-0002-3709-4245
}

\begin{abstract}
In this article the author considers the penitentiary socionics, that directed to the direction of scientific support on the criminological study of interpersonal relations among convicts. In the research, it became clear that the personal relationships of convicts in the process of serving their sentences in places of deprivation of liberty form a relatively independent structure functioning in the system of official relations of the microenvironment of penal institutions. Having analyzed the scientific works author stress out the importance of the socionics knowledge, especially to implement in the educational process with inmates. Summarises the concept of practical use of knowledge about personality of convicted staff in a penitentiary institution.
\end{abstract}

Keywords:

socionics, penitentiary system, crime, inmates, victims, convict, adaptation.

\section{Introduction}

Back in the 80 s of the last century, Soviet professor I.V. Shmarov, in the preface to the monograph "The Microenvironment of Convicts in Correctional Institutions," wrote that "the microenvironment acts as a significant sociopsychological factor that to a certain extent reduces the effectiveness of the educational impact on the personality of the convict. In this regard, sociological and socio-psychological studies of the problem of the microenvironment of persons serving sentence and its impact on the process of correction and re-education of convicts are of particular actuality and importance, especially since many aspects of this problem have not yet received sufficiently full and deep coverage in the special literature"[1].

The data obtained in the course of the research, allows us to conclude that the overwhelming majority of convicts (up to 90\%) form unofficial small groups, the average number of which varies from two to seven people. As I.V. Shmarov correctly noted, "Educators of colonies should in every possible way stimulate positive intra-group and inter-group contacts of convicts, which creates favorable conditions for the formation of a collective of convicts in the colony"[2].

The study of the personality of criminals and the structure of relationships in their environment is impossible without identifying the types of criminals with their characteristic features of personal qualities and behavior.

It is clear that the classification of the relations of criminals cannot be carried out in isolation from the general psychological classification of individuals, for there are no special "criminal features" in the human psyche [3]. This allows us to use the latest theoretical developments fully in socionics to study the environment of criminals. At the same time, it is possible and necessary to make some amendments, taking into account the position of the greatest Russian psychologist A.F. Lazursky. He reasonably emphasized that the perverse development of the human personality is associated not with the absence or insufficiency of certain mental qualities (mind, will, emotions, thinking), but mostly with a discrepancy between the characteristics of the psyche and those external conditions in which human development occurs [4]. 
Currently, it is recognized in human science that the main author of the theory of interpersonal relationships is Augira Augustinavichute. The researcher and founder of socionics as a science A. Augustinavichute added the proposal to the four types of information identified by C. Jung [5]; this proposal are the mechanisms for processing information from the outside and the mechanisms of information coming from within a person should be different. In this regard, each of the 4 types of information received two modifications: subjective and objective. Augustinavichute introduces the concepts of "intratim" and "extratim" as opposed to "introvert" and "extrovert". Social psychology knows that interversion and extraversion are qualities, states inherent in a person in a particular situation. Moreover, in socionics it is determined that introtimality and extratimality are properties inherent in a person constantly. In a word, now we can confidently conclude that both an introverted extratym and an extraverted introtim may well exist. This is informational metabolism or the first reference points in the preparation of descriptions of socionic portraits [6].

Socionics allows each employee of institutions for the execution of punishment and each convict not only to develop his capabilities, which he sometimes does not even know about, but also allows him to choose his life path correctly, assessing his strengths and weaknesses, and, therefore, correctly and rationally to apply their strengths, talent, skills, adequately build their relationships with the environment. Socionics can give not some abstract general for all cases of life, but, consequently, ineffective advices, namely, specific recommendations for each socionic type, for each employee, for any convict, based on the specific psychological environment in which he lives and works.

Awareness not only of oneself as a representative of one of the socionic types, but also of another - an interlocutor, friend, employee, criminal, whose thinking and behavior obey certain laws and may not be similar to your own thinking and behavior, allows you to avoid many mistakes in communication. Only using certain personal or personified educational techniques that are acceptable for a specific socionic type of offender you can achieve better results.

\section{Methods}

In the research work, methods such as historical, systemic and structural, comparative legal, logical, specific sociological, complex analysis of scientific sources, induction and deduction, analysis of statistical data were applied. Also in his work, the author attempted a comprehensive approach to the study of the personality of convicts in penal institutions. By studying the experience of the penitentiary system in Uzbekistan, the author conducted a comparative analysis of some scientific works.

\section{The Main Part and Analysis}

Socionics allows us to take into account the strengths and weaknesses of an individual, without setting him unsolvable tasks for a given socionic personality type. Knowledge of socionics allows to purposefully form the most stable collectives (units, brigades, detachments) of convicts with an optimal socio-psychological climate in extreme conditions, when the human factor becomes decisive, in prisons. This is especially important for places of deprivation of liberty and strict isolation, i.e. penitentiary institutions, which are a closed system with a high concentration of socially deformed individuals with a perverted system of attitudes and views on other people. Here, a person's capabilities, his communicative, cognitive, and even more ethical and aesthetic needs are in a state of deprivation, a sharp limitation. In the meantime, individuals embark on the path of improving their criminal qualifications. They strive to meet the expectations of the criminal environment and the subculture of the criminal community in a best way. The criminal subculture provides a stable criminalization of the personality, its desocialization. Within the framework of the criminal subculture, it is easier for a person with defects in socialization and mental self-regulation 
to assert himself. There is a hypercompensation of "weak points", unconditional acceptance of ritual modes of behavior and criminal ideology ("laws").

Corrective or penitentiary (from Lat. Poenitentiarius - "penitential", "corrective") socionics, like psychology, studies the psychological basis of resocialization - the restoration of previously disturbed social relations and qualities of the individual which are necessary for his/her full life in society. All factors of interpersonal relations of convicts, mechanisms within personal alteration, as well as the necessary conditions for the formation of socially adapted behavior of the individual are taken into account by our proposed penitentiary socionics. We agree with Salayev N.S. that right of the convict to life is of a natural nature and as social value gets its expression in the political and legal acts of the state. This right is enjoyed by all citizens, including those sentenced to imprisonment [7].

We take three main directions as general directions of the resocializing component of penitentiary socionics:

- psychological diagnostics of the personal traits of each convict and the identification of specific defects in his general socialization, as well as ways of his mental self-regulation to eliminate these defects;

- carrying out of the necessary measures of psychotherapy, relaxation, leveling of personal accentuations, psychopathic manifestations, and removal of all kinds of psychological barriers, manifestations of exaggerated psychological protection from the educational environment;

- all-round restoration of the disturbed social relations of the individual, mobilization of his/her mental activity for corrective contacts, the formation of a socially positive sphere of her current and future goal-setting in the field of communication based on socially positive value orientations.

The advantage of the proposed penitentiary socionics lies precisely in the fact that even from a few facts one can learn a lot about the personality of a criminal (as well as any person). To do this, it is necessary to establish to which socionic type of informational metabolism a citizen belongs, to present a model of this type and already from it "read" his habits and intentions, needs and views, behavior and interpersonal manifestations. Socionics will help determine what kind of relationships (favorable or conflicting) can develop with this person and teach how to correct them.

\section{Programs of studying the personality and environment (medium) of convicts \\ Programs of studying the personality of convicts}

The word "program" in translation from Greek means "announcement, prescription" and has two meanings:

1) A plan of the planned activity, which defines the main goals and objectives, the main means and ways of their existence;

2) A set of a system of measures aimed at solving a specific problem. The program establishes the phasing of the implementation of the tasks associated with this, the specific means of their implementation, the required results [8].

The methodological part includes:

- Definition of the problem under study, object and subject of research;

- The formulation of the goal and objectives of the research;

- Clarification of the basic concepts that characterize the object and subject of research;

- A preliminary description of the object;

- Formulation of working hypotheses.

The procedural part consists of the following sections:

- Plan that provides for the stages of the research;

- Description of methods and techniques for data collection;

- Description of the methods for analyzing the data obtained.

Each section of the procedural part of the program may include a certain set of specific methods, techniques, working documents and instructions. 
For a successful study of the personality of convicts, it is necessary to have a program that defines the range of information to be studied. It is indicative in nature and may vary depending on the goals and objectives of studying personality, as well as other factors. A sample program might include:

a) Information - biographical and sociodemographic (surname, name, patronymic, year and place of birth, education, profession and work experience, health status and attitude towards it, marital status, age at which the crime was committed);

b) Information about:

Microenvironment and conditions of personality formation (profession and form of activity of parents, influence of other family members on the convict);

Material security of the family; relationships and moral and psychological climate in the family;

Period of study at school, academic performance; relationships with peers and teachers;

Types, methods and forms of leisure activities;

The presence (bringing) to the internal affairs bodies;

The reasons and conditions for the occurrence of criminal behavior;

The presence of mental disorders in personality development;

Facts of alcohol or drug use, vagrancy, as well as about the street environment, the orientation of the small group;

c) Information about:

The crime committed and attitude towards it (about the circumstances and conditions of the crime);

The motives and purpose of the crime;

Position in a criminal group (leader, follower, outcast, etc.);

Roles in the crime committed (organizer, perpetrator, inciter, harbourer, etc.);

Behavior during the investigation and in court (frankly confessed or locked himself in his testimony, whether he resorted to perjury, deception or helped investigation and court in ascertaining the truth);

Changing motives in the course of committing a crime, in the process of investigation and trial;

The judgment of the court and the attitude in it, the awareness of guilt, the degree of remorse, the desire to compensate for the damage caused.

d) Information about the personality traits associated with:

\section{orientation [9]:}

The level of development of needs (material and spiritual) and the degree of their harmony;

In the motivational sphere, the prevailing motives of behavior in the institution for the execution of punishment and their characteristics (by spheres of life and activity: regime, work, study, leisure, social work, etc.);

Interests and inclinations: in what areas of life they are manifested, their breadth, stability, depth;

Ideals (moral, aesthetic), their influence on behavior;

Views and beliefs;

Worldview, reasoning about life, about the purpose of a person;

Value orientations;

Goals and plans in life (close, middle and distant), their ratio;

The general correlation of the orientation of the personality and the committed crime (the crime is accidental, possible, due to the orientation of the personality, is completely determined by the orientation of the personality);

General conclusion about the level, breadth, stability and effectiveness of directionality, directional correction;

\section{Temperament:}

Extroversion, introversion, emotional reactivity;

The pace of mental and motor reactions;

Ease (difficulty) of transition from one type of activity to another, adaptation to new conditions;

Stability - lability; 
Work capacity and physical endurance (large, medium, weak; episodic, cyclical);

Communicativeness (increased, normal, decreased);

Dependence of behavior on the current situation (large, medium, weak);

The conclusion about the prevailing type of temperament, its influence on the committed crime and behavior during the investigation, in court, in a investigatory isolation ward and in a penitentiary institution;

\section{Character:}

In relation to work (hardworking, efficient);

In relation to people (sociable, unsociable, uncommunicative, attentive, inattentive, rude, altruist, altruism is poorly developed, egoist);

In relation to the interests of the collective (collectivist, collectivism is poorly developed, individualist);

In relation to himself (self-critical, not selfcritical enough, not self-critical);

on self-esteem and level of pretension (overestimated, adequate, underestimated).

\section{Basic and general character traits:}

honesty, collectivism, discipline, independence;

being active, being initiative, orderliness, optimism, stability, etc.;

strength, fullness, integrity, certainty of character;

the degree of its criminal infection;

the influence of character on criminal behavior;

accentuation of character;

deviations in character caused by deprivation of liberty;

the main directions of character correction;

\section{capability:}

(general and special), level of development (high, medium, low);

manifestation of abilities in criminal activities;

professional suitability, recommended professions or specialties for mastering in a penal institution; opportunities for the development of the convicted person's abilities;

ability and activity in a penitentiary institution;

e) about the features of mental processes and states:

\section{psychical conditions:}

most frequently recurring and their impact on personality;

dominating before committing a crime, in the course of criminal activity, during the investigation, in court, while in a remand prison, during the adaptation period, in subsequent periods of serving the sentence, on the eve of release;

psychical states manifested in various activities, their pathology;

\section{emotional and volitional sphere:}

content and prevailing forms of expression of emotions and feelings;

external expression of their ability to control their experiences.

emotional personality traits: responsiveness, callousness, cheerfulness, pessimism;

deficiencies in emotional development: increased emotional sensitivity, affectivity, instability of mood, severe excitability, anxiety and fear, lethargy and depression, sadness, fear, moodiness, tearfulness, gloom.

will and its direction;

basic volitional qualities and the degree of their manifestation in overcoming difficulties;

emotional and volitional stability, readiness for mobilization;

the manifestation of emotions and will in criminal behavior;

in the process of investigation, trial and serving a sentence.

\section{intellectual and cognitive sphere:}

the severity of attention, its basic features and violations;

perception, its adequacy (inadequacy); the impact of incarceration on perception; manifestations in the life of convicts, possible memory disorders; 
imagination, the degree of its development and manifestation in criminal activity, in various tricks, deviations in the field of imagination;

thinking: the ability to analyze and synthesize, the most developed senses of the mind (quick wit, resourcefulness, flexibility, depth, breadth);

manifestations of thinking in criminal activity, during the investigation, in court, while serving a sentence;

speech: vocabulary, use of jargon, expressiveness of speech, consistency, consistency;

deviations in intellectual activity;

f) about special signs:

tattoos - where applied, their content;

nicknames - where, when and for what they were received;

reflection in the clinic and tattoos of the social status of the individual;

g) on the behavior of the convicted person in the institution for the execution of punishment:

participation in the life of amateur organizations, his motives;

the system of established interpersonal relations;

participation in school and production areas (motives, willingly or unwillingly), work in production;

spheres of life that arouse special interests of the convict;

changes in the behavior of the convict during resocialization - revision of the meaning of life, change of attitudes;

attitude to educational influences - the severity of internal resistance, methods and means of "psychological defense";

the degree of correction: proved his correction, firmly took the path of correction, took on the path of correction, himself did not correct, worsened his behaviour, a malicious violator;

h) about the forecast of individual behavior:

what can be expected from a convicted person in the present and future;

proposals for its further resocialization and social adaptation in conditions of freedom.
The program should not limit the psychologist's initiative in studying the personality of the convict. It helps to avoid haphazardness in obtaining and fixing information- about the person, facilitates the compilation of a psychological characterization of the convict, is its scheme.

It should be noted that the professional approach of a psychologist should be guided by proven programs.

\section{Discussion}

The most successful from a practical point of view is the program of K.K. Platonov [10], developed in the 80s of the last century on basis of personality structure. It highlights sections on demographic data, abilities, general character traits. In addition, it has four substructures: orientation, personality experience, individual characteristics of mental processes, and a biologically determined substructure. All of them are equipped with the appropriate criteria. This structure served as the basis for the development of a program for studying the personality of convicts and can be used both fully and partially.

In this regard, the program for studying the personality of a convict in a penitentiary institution, developed by Y.M. Averkiev and V.G. Deev [8].

It involves the study of abilities, orientation, professional knowledge and skills, individual abilities of mental processes and states, temperament, the level of development of morality and legal awareness. The authors proceed from the fact that the program for studying a specific personality can be continuous and selective. When conducting a selective study of the general program, the necessary structural component is highlighted, which is developed in more detail. The study involves the use of a set of methodological techniques and the participation of many persons with whom the convict communicates.

In the program I.P. Bashkatov[9], on the study of the personality of a juvenile convict, the following sections are distinguished: 
a) attitude towards isolation from society:

- was very upset by arrest, isolation;

- was depressed, cried;

- was withdrawn, had difficulty coming into contact with others;

- complained of deteriorating health, mental and functional disorders were observed;

- refused food;

- made attempts to self-harm;

- was excited, aggressive, embittered;

- feigned a mental disorder;

- arrest, isolation suffered relatively easily;

- quickly got used to the new situation in the colony;

b) character:

- attitude towards the committed crime;

- attitude to the requirements of the regime;

- attitude to work and study;

- relationships with other convicts;

- attitude towards oneself;

- attitude towards relatives;

c) mental development, interests and inclinations;

d) moral development;

e) communicative features;

f) volitional features;

g) lack of emotional development;

h) deviations in mental development.

The program also includes a section that allows you to determine the characteristics of behaviour, possible deviations in personality. The section "Main directions and types of activities to overcome deviations in the development of the convict's personality" contains a list of measures of influence and the main types of activities in which the convict must be included. The section "Deviation in the development of personality and the leading directions and types of activities to overcome them" sets out the techniques and methods of drawing up an approximate program to correct the personality of a convict. Programs for studying the personality of convicts, developed by L.A. Vysotin and V.D. Lutansky, aimed at differentiating and individualizing educational work with convicts [11]. There are also known programs for the study of prisoners in quarantine.
A large number of prisoners are studied abroad, the most indicative of them is V.Fox's program, which distinguishes the types of criminals and measures of influence on them [12].

Thus, there are general and particular (which are isolated from the general or compiled specially) programs for studying the personality of convicts [13]. There are study programs that include methods of influence, as well as programs that study mainly the pedagogical aspect [14]. Special programs are developed to study a convict in quarantine, during the main period of serving his sentence, during the period of preparation for release, as well as for certain categories of convicts requiring special study. The study of the personality of the convict involves three main stages - adaptation, correction and readaptation.

The stage of adaptation (2-3 months) coincides with the arrival of the convicted person in the colony and his stay in quarantine. The psychologist (researcher) analyzes the life path and attitude of the convict to the environment: strive to identify life situations, objective and subjective conditions that contributed to the consolidation of asocial motives of behavior, to draw up preliminary characteristics, to develop methods of influencing convicts in order to resocialize.

The stage of correction is experimental, it is implemented through a survey, observation, interviews, analysis of independent characteristics, testing, systematic study, development of resocialization programs.

The stage of readaptation (two to three months before release) is associated with the preparation of the convict for release. The psychologist identifies the goals, life positions, plans of the convict. The effectiveness and reliability of psychological diagnostics of convicts is achieved by the complex application of these techniques. For example, the motivation of convicts can be studied through interviewing, questioning and testing according to special adapted methods. In the course of written interviews, the most common motives of the convicts are revealed. In the written interview 
form, the main motives are grouped, which the convicts are asked to rate on a five-point scale. Interviewing allows you to identify the severity of a particular motive and their groups, as well as to rank them and substantiate the hierarchical structure. The hierarchy of motives is determined in accordance with their relevance for the convicted. In each position on the scales, the sum of the points scored is calculated. The points are ranked, then the rank places of the motives of the groups are determined. The resulting value, which expresses the ratio of the actual rank to the maximum possible, is the hierarchy coefficient (Co). The interviewing method in relation to the study of the motivation of convicts is very informative and useful. It allows you to establish and describe the motives of the convicts, which they are aware of.

In accordance with the concept of A.N. Leontiev's [15] motives are not always recognized by convicts (they are not separated from consciousness, but are psychically reflected in a specific form - the emotional colouring of behaviour and activity). The convicts are not always truthful and openly answer the questions of the written interview, therefore, it becomes necessary to use special adapted test methods that exclude direct interpretation of the answers and are aimed at identifying the dominant motives of behavior and activity. One of them is the original compact THP technique (test of humorous phrases), developed by V.S. Babina and A.G. Shmelev, which allows you to combine standardized rapid test meters with individualized projective technique [16].

The methodology is based on the principle of thematic classification of ambiguous stimuli (humorous phrases). Convicts classify polysemantic stimuli according to personal motivation and assign the same phrases to different tests (thematic constructs). The increased motivational significance (dominance) of the topic leads to the fact that the convict perceives this particular topic in ambiguous stimuli and ignores all the rest as secondary. As a result, the number of incentives attributed by convicts to one topic sharply exceeds the number of incentives attributed to other topics.

Incentive material is a set of 100 humorous phrases printed on a special letterhead. 40 phrases uniquely relate to one of 10 topics (4 phrases per topic), and 60 phrases are ambiguous (convicts indicate different topics for the same phrase). All phrases used in methodology were published in modern domestic satirical and humorous journals.

In the adapted version of the HPT, the following themes (motives) stand out: 1) sadism; 2) sex; 3) addictions; 4) money; 5) fashion; 6) career; 7) family troubles; 8) social turmoil; 9) mediocrity in art; 10) stupidity.

In the process of work and interpreting the test results, a motivational analysis of thematic constructors is carried out. The formation of a stable thematic constructor (a large class of humorous phrases) is considered as an increased tension (significance) of the corresponding motivational theme.

The test form is counted by summing the number of phrases in the corresponding class without using a key. Ten indicators calculated in this way are visualized as profiles and are compiled into special analytical tables.

In the process of analysing the motivational profiles of the HPT, it is necessary to take into account not only the strength of the actually satisfied motive, but also the strength of the obstacle blocking satisfaction, for example:

1) sadism: motive - self-preservation; obstacle - various "aggressive" factors that threaten the physical integrity of the employee;

2) sex: motive - entering into an intimatesexual relationship, relieving tension from sexual dissatisfaction; obstacle - internal difficulties (lack of attractiveness, modesty) and social prohibitions on sexual relations outside the family, internalized by the convict;

3) addictions (drunkenness): motive - the use of alcoholic beverages, relieving stress by pharmacological means; obstacle - social prohibitions internalized by convicts, manifested in feelings of guilt, shame, as well as external difficulties (threat of administrative and 
disciplinary responsibility, high cost of alcoholic beverages, tranquilizers);

4) money: motive - the material well-being of the convict; obstacle - lack of money, high prices for goods and services;

5) fashion: motive - self-feed, prestige, selfaffirmation by the possession of external attributes of social success; the obstacle is a change in fashion and the high price of prestigious goods;

6) career: motive - achieving a high position in society, promotion and gaining wide recognition; obstacle - competition, the presence of compromises, humiliation;

7) family troubles: motive - family wellbeing, self-expression in family relationships; obstacle - behaviour of family members that does not meet the expectations of the convict, objective difficulties (material and other problems);

8) social troubles: motives - social wellbeing; obstacle - asocial behaviour of the employee, lack of awareness of social norms;

9) mediocrity in art: motive - the search for beauty, harmony, aesthetic sentimentality; obstacle - the presence of various works of low aesthetic quality;

10) stupidity: motive - knowledge, striving for truth as an independent value, self-affirmation in the possession of true knowledge; the obstacle is ignorance, the limitations of others.

When interpreting the test data, it is advisable to analyse these topics taking into account their possible combination, combinations in increasing and decreasing the motivational tension of pairs of topics.

In order to distinguish between the subject and obstacle content of actual motivation, additional psycho-diagnostic information obtained through other tests, questionnaires, interviews, analysis of independent characteristics, and the biographical method can be used.

It is advisable to study the orientation of the personality of the convicts with the help of A. Bass's adapted orientation questionnaire, consisting of 27 points-judgments, for each of which there are 3 possible answers, corresponding to three types of personality orientation [17].
Convicts choose one answer that most expresses their opinion or corresponds to reality, and another that is most distant from their opinion or least corresponds to reality. The answer "most" is estimated at 2 points, the "least" - at 0 points, the remaining unselected - at 1 point. The points scored on all 27 points are summed up for each type of focus.

With the help of this technique, it is possible to identify the orientation of convicts to myself (I) - orientation towards direct reward, aggressiveness in achieving status, imperiousness, a tendency to compete, irritability, anxiety, introversion. Focus on communication (C) - the desire to maintain relationships with people under any conditions, focus on joint activities, but often to the detriment of performing specific tasks, focus on social approval, dependence on the group, the need for affection and emotional relationships with people. Focus on a case (C) - interest in solving case problems, doing the job as best as possible, focus on cooperation, the ability to defend their own opinion, which is useful for achieving a common goal.

To determine the "threshold of activity" (the degree of difficulty and ease of performing actions, decisiveness in actions, striving for constant activity or, conversely, for passivity, a closed lifestyle), one can use the "Threshold of activity" (TA) technique developed by T.L. Romanova [18]. It allows you to receive psychodiagnostic information, with the help of which you can classify convicts according to relevant qualities.

The TA questionnaire consists of 18 statements formulated in the first person to increase the reliability of the survey results. The standard answer sheet is processed using a key. For an answer that matches the key, 1 point is awarded, for a mismatch - 0 points. Then the total score is calculated, which is compared with the test norms, and a conclusion is made for each convict.

The reliability of the entire test is described using the Kyuder-Rigardson test and is 0.66, which meets the requirements for the homogeneity 
of the scale [19]. Reliability - the consistency of individual items - is calculated using the bi-serial correlation coefficient of each item on the scale with the total score. All 18 items used have a significant hierarchy with a total score and an error probability of less than $5 \%$. The validity of the test is ensured by comparing the intuitive selfassessments of convicts and objective test results, as well as comparing the results of TA with other psycho-diagnostic techniques.

To study the characteristics of convicts, you can also use the Bass-Darki questionnaire [17]. With the help of it, aggression is investigated as one of the common ways of solving problems that arise in non-standard (frustrating) situations that cause increased mental tension [24].

In general, aggression can be viewed as motivated destructive behaviour that contradicts the norms and rules of people's existence in society, harming the objects of attack, causing physical damage or causing them mental discomfort (negative experiences, a state of tension, fear, depression, etc.).

The questionnaire consists of 8 subscales representing the most relevant indicators of aggression. With its help, it is possible to identify the forms of aggression and hostile reactions in convicts: physical and indirect aggression, a tendency to irritation, negativism, resentment, suspicion, verbal aggression and guilt.

The text of the questionnaire contains 75 statements with which the convicts agree or not, according to the number of coincidences of the answers of the convicts with the test key, the indices of various forms of aggression and hostile reactions of the convicts are calculated [26].

The proposed programs contain only the most important questions, the knowledge of which is necessary, as a rule, when studying the personality of each convict. This, of course, does not exclude the possibility that in the process of correcting individual convict other issues not mentioned here may arise. Likewise, the caregiver may omit some of the questions that do not need to be investigated about the person.
The list of questions set out in the program, naturally, cannot be studied simultaneously or within a very short period of time. The sequence depends, first of all, on the personality characteristics of a given person, on what the caregiver recognizes as more important and urgent [27].

The program for studying the personality of a convict, at first glance, may seem very extensive, requiring too long a period of time for its implementation. In our opinion some necessary measures should be taken on the legislative base. For instance, the legislator threatens to impose criminal penalties for such crimes as

imprisonment, restriction of liberty, fine, imprisonment of a certain right, compulsory community service, correctional labour, etc. [20].

In fact, it is not so. Many of the information named here are always in the field of view of the educator [21]. In comparison to the process of investigation, it is more likely different, because at the time of the initiation of the criminal case, the person who committed the crime is known to the investigation [28].

However, here the information necessary for the caregiver is brought into a certain system, in which gaps, missing links are immediately visible. In addition, as practice shows, the time spent will pay off more than in the process of working with convicts [22]. Knowing them well, the caregiver gets the opportunity to more successfully carry out correction and re-education, achieving the goals in a shorter time and with the least labour.

\section{Conclusion}

One of the most important tasks of punishment is the correction of the convict, which is impossible without studying his personality, identifying those traits that led to the commission of a crime and must be eradicated. On the other hand, it is important to know the good that is in a person, on which one can rely in conducting educational work. R. Abdullaev rightly notes that at this time all over the world and in Uzbekistan, due to the unfavorable epidemiological situation due to COVID-19, quarantine has been declared, 
movement in the city has been limited, a number of restrictions have been introduced on visits to state bodies, enterprises, institutions and other public places. Along with them, the buildings of law enforcement bodies, institutions for the execution of punishment, and pre-trial detention centers are also closed, because of this, it is difficult to carry out some necessary actions [23]. It is believed that without studying the personality of the convict, it is impossible to effectively apply penalties and incentives, change the conditions for serving the sentence, transfer convicts from one type of correctional institution to another [25]. Studying the personality of the convict helps to solve a number of practically important issues of the functioning of places of deprivation of liberty: recruiting brigades and detachments, forming amateur organizations, general and vocational schools, individualizing educational work. Finally, the study of the personality of the convict makes it possible to judge the results of correction and, consequently, the possibility of presenting the convicted person to parole, to replace the unserved part of imprisonment with a milder form of punishment or to pardon, and it is correct to apply amnesty. From the above, it is clear that almost all the activities of the correctional institution are in one way or another connected with the study of the personality of the convict.

The duty to study the personality of convicts is enshrined in the law. Part 4 of Art. 109 of the PEC of the Republic of Uzbekistan establishes that "educational work with convicts is carried out taking into account the individual characteristics of the personality and nature of the convicts and the circumstances of their crimes." The process of studying the personality of convicts presents significant complexity, primarily, because the circumstances and signs that characterize the personality are very numerous. This raises the question of their classification.

All signs of a convict's personality can be grouped and identified socio-demographic, criminal law and criminal executive characteristics [26].
The socio-demographic characteristics of a person include the features and characteristics inherent in convicts as biological individuals and citizens of the state. Although the perpetrators of committed crimes are characterized by certain characteristics related to socio-demographic characteristics (for example, a younger age, a low percentage of people with higher education, a significantly higher percentage of those who do not have a family, etc.), all socially citizens have demographic characteristics, regardless of their law-abidingness.

The study of information concerning the criminal activity of the convict is important for the organization of the entire correctional process, in particular educational work, labor, regime, especially the prevention of crimes [27].

Among this information should include data on the qualification of the crime committed and the appointed term of punishment, about the possibility of parole, the role of the person in the crime. It is important to know how active he was in the implementation of a criminal plan, played the role of an organizer or was a minor participant, whether he committed a crime in case of a recidivist, a particularly dangerous recidivist [28].

It examines data on the qualifications of the crime committed, the number of convictions, the sentence imposed, etc.

The criminally-executive characteristic of convicts concerns serving convicts Punishment. She is essential. Studying the convict for a considerable time, the administration of the correctional institution really sees what changes are taking place under the influence of the regime, labor, educational work, which of the means of influence turn out to be the most effective.

\section{References}

[1] Shmarov I.V. Microenvironment of convicts in correctional institutions: Monograph. - M.: All-Russian Research Institute, Ministry of Internal Affairs. 1979. -P. 3. 
[2] M.I. Enikeev Foundations of General and Legal Psychology. - M.: Jurist, 1999. - P. 301-302.

[3] Lazursky A.F. Personal classification. - L.: University, 1924. -P. 27.

[4] Jung K. There are many unreasonable things in the prison system // Man: crime and punishment. - Moscow, 1994. - No. 1 (2). - S. 13-15.

[5] Augustinavichute A. The dual nature of man. * Augustinavichute A. Socionics: Introduction. (1998) Socionics: Psychotypes.

[6] Detkov M.G. Educate a citizen. Forms and content: Textbook. - Domodedovo: Interdisciplinary Institute for Advanced Studies of the Department of Internal Affairs, 1991. - P. 63-68.

[7] Volkov I.P. Sociometry as a method of social psychology. - L .: University, 1968.

[8] Pirojkov V.F. The orientation of the personality and the motives of the activities of those sentenced to imprisonment. - M. All-Russian Research Institute, 1967.

[9] Platonov K.K. The Greatness of Simple Hearts: Favorites. 1975

[10] Averkiev Yu.M., Deev V.G. The program for studying the personality of a convict in a correctional institution. - I.: Political department of forestry ITU, 1973.

[11] Bashkatova I.P. Psychology of juvenile delinquent groups. - M.: Psychology, 1993.

[12] Vysotin L.A., Lutansky V.D. Methodology for studying the individual personality traits of a student prisoner. - M.: Political department, RSFSR, 1966.

[13] Averkiev Yu.M., Deev V.G. The program for studying the personality of a convict in a correctional institution. - M.: Political department of forestry ITU, 1973.

[14] Bashkatov I.P. Decree. Psychology of juvenile delinquent groups. - M.: Psychology, 1993

[15] Leontiev A.N. Needs, motives, emotions / - M.,1971
[16] Babina V.S., Shmelev A.G. http://www.vashpsixolog.ru/psychodiagno stic-school-psychologist/59-diagnosismotivational-sphere/186-test-humorousphrases-tuv

[17] Bass A. Aggression Level Research Questionnaire

[18] T.L. Romanova. Activity threshold personal questionnaire

[19] Kyuder-Rigardson, Psychological test reliability. https://ru.wikipedia.org/wiki

[20] Kurbanov, M (2018) "GENERAL DESCRIPTION OF CRIMES RELATED TO OBSTRUCTION, UNLAWFUL INTERFERENCE IN BUSINESS ACTIVITY," ProAcademy: Vol. 1 : Iss. 4 , Article $14 . \quad$ Available at: https://uzjournals.edu.uz/proacademy/vol1/ iss $4 / 14$

[21] Kurbanov Marufjon Mamadaminovich. SOCIAL NEED TO DETERMINE LIABILITY FOR CRIMES RELATED WITH OBSTRUCTION, ILLEGAL INTERFERENCE IN BUSINESS ACTIVITY. Journal of Law Research. 2020, special issue 3, pp. 197-208. http://dx.doi.org/10.26739/2181-91302020-SI-3-24.

[22] Курбанов М. М. ПРЕСТУПЛЕНИЯ, СВЯЗАННЫЕ ВОСПРЕПЯТСТВОВАНИЕМ, НЕЗАКОННЫМ ВМЕШАТЕЛЬСТВОМ В ПРЕДПРИНИМАТЕЛЬСКУЮ ДЕЯТЕЛЬНОСТЬ В РЕСПУБЛИКЕ УЗБЕКИСТАН //АКТУАЛЬНЫЕ ПРОБЛЕМЫ ЮРИСПРУДЕНЦИИ. 2020. - C. 56.

[23] R.K. Abdullaev. PROBLEMATIC ISSUES OF THE CRIMINAL PROCEDURE LEGISLATION. Journal of Law Research. 2020, special issue 3, pp. 250-256.

[24] Khidoyatov B. Stages Of Legal Regulation Of Inquiry In The Republic Of Uzbekistan. The American Journal of Political Science 
Law and Criminology. 2020 Nov 30;2(11):179-86.

[25] Kadirova M., Abdullaev R., Khujanazarov A., Rahimkulova L. Evaluation of the results of judicial computer and technical expertises by the investigators and the court.

DOI:

10.37200/IJPR/V24I6/PR260256.

https://www.psychosocial.com/article/PR2 $\underline{60256 / 13667 /}$

[26] Eldarovna, G. N., Ochilov, K., \& Sobirov, B. (2019). Problems of transplantation of human organs and tissues: international standards and international experience. Religación. Revista de Ciencias Sociales y Humanidades, 4(16), 714-719.

[27] Ochilov, X., \& Kamalova, D. (2020). Criminal responsibility for inchoate offence according criminal code of the Republic of Uzbekistan. International Journal of Advanced Science and Technology, 29(5), 1729-1737.

[28] Topildieva, D. (2020) "Circumstances to be determined when investigating intentional killing", TSUL Legal Report International electronic scientific journal, 1(1). Available at: https://legalreport.tsul.uz/index.php/journal /article/view/18

(Accessed: 14December2020). 